\title{
EDITORIAL
}

\section{MAN AND THE ANIMALS ARE MERELY A PASSAGE AND CHANNEL FOR FOOD LEONARDO DA VINCI, 1452-1519}

\author{
Dan L. Waitzberg
}

WAITZBERG DL - Man and the animals are merely a passage and channel for food - Leonardo da Vinci, $1452-1519$. Rev. Hosp. Clín. Fac. Med. S. Paulo 58(1):1-4, 2003.

Nutritional therapy in the critically ill patient in the intensive care unit (ICU) is an important part of the total care of the patient. Nutrition can be given through parenteral nutrition or enteral nutrition therapy. Parenteral nutrition has been limited recently, but not exclusively, to patients who, for a variety of reasons, cannot be fed enterally. Although the debate concerning parenteral versus enteral nutrition continues ${ }^{1-4}$, enteral nutrition is preferred whenever tolerated because of its potential less risk of infection, no need for central vein catheterization, improved gastrointestinal function, and decreased cost. Nevertheless, the use of this technique is limited by several technical problems and their related complications. It includes the lack of reliable access, high gastric residuals, gastroesophageal reflux, em- esis, tracheal aspiration, diarrhea, and constipation $^{5}$.

In this issue of Rev. Hosp. Clin. Fac. Med. S. Paulo, a multiprofessional group of health practitioners investigated whether there are advantages of continuous versus intermittent administration of gastric enteral nutrition in ICU patients.

In a prospective randomized study, Serpa and colleagues ${ }^{6}$ enrolled 28 consecutive critically ill patients receiving mechanical ventilation and nasogastric feeding and divided them into two groups, those given continuous enteral nutrition or intermittent (8 aliquots at 3 hours intervals). Therapy was limited to 3 days of enteral nutrition, and residual gastric volume and compliance with the dietetic prescription were chosen as the end point. Enteral diet was marked with aniline-blue dye to recognize pulmonary aspiration and pneumonia was diagnosed when new lung $\mathrm{X}$ rays alterations were associated to clinical symptoms. Residual gastric volumes were high in both groups. Pulmonary aspiration was suspected in both groups but confirmed just in one (continuous feeding). Total daily enteral nutrition intake was smaller than originally programmed volume in both groups and the reasons for interrupting enteral nutrition were referred as high residual volume as well as medical procedures.

Of note was that enteral nutrition complications were high gastric residual in almost half of the patients, diarrhea in $14.3 \%$ and feeding tube displacement in $25 \%$. These complications might be the reason why almost $20 \%$ of the patients had registered deficits in the dietary intake superior than the $40 \%$ origi- 
nally prescribed. The authors conclude that both modalities of enteral nutrition administration displayed a deficit of actually supplied volume, what could be considered justified when enterally feeding critically ill patients.

This study of enteral nutrition in the ICU patients receiving enteral nutrition joins a number of published results worried about the safety of this technique and its nutritional efficiency in this setting.

The site of enteral feeding administration is important. Only $50 \%$ of healthy volunteers who were fed a polymeric diet intragastrically presented normal postprandial motility while all of these volunteers showed normal postprandial motility when fed intraduodenally. During intraduodenal feeding, a fed motility pattern is preserved, whereas during intragastric feeding transition from a fed to a fasting motor pattern is observed in over $50 \%$ of the subjects. These differences may be related to augmented hormone release during intraduodenal feeding ${ }^{7}$. In volunteers receiving dopamine, gastric emptying time was delayed and orocaecal transit was prolonged ${ }^{9}$. In ICU ventilated injured patients requiring morphine it was observed antral hypomotility but persisting duodenal activity fronts during continuous intragastric feeding ${ }^{12}$.

In order to deal with the problem of inadequate gastric emptying with resultant high gastric residuals, the feeding tube can be placed beyond the pylorus. This procedure can be achieved through, in difficult cases, by endoscopic or radiographic techniques.

The issue of continuous versus cyclic enteral nutrition was addressed before. In patients submitted to a pylorus-preserving pancreatoduodenectomy and fed through a needle catheter jejunostomy, it was observed that cyclic enteral nutrition reduced the number of days until patients tolerate a normal diet, partially due to hormonal changes in humoral feedback mechanisms ${ }^{7}$. However, when gastric emptying was analyzed in a similar group of patients, the authors verified that enteral nutrition infused through a jejunostomy increased the gastric emptying delay when compared to noenteral (parenteral) nutrition 9,10.

The observed Serpa's results may have suffered from the small number of patients included in this study, as well as from the short period of observation. This reflects the high variability of the ICU patients not being easily categorized under the inclusion and exclusion criteria adopted.

Gastric stasis is frequent in ICU patients and may increase gastric colonization with bacteria. In the event of reflux to the lung it contributes to respiratory infection. Periodic aspiration of gastric content is classically used to assess gastric emptying of enteral nutrition. However results are operator dependent and subjected to mistakes.

In order to identify gastro tracheal reflux, clinically available methods have been proposed like the appearance of blue dye in the suctioned tracheobronchial secretions and the dosage of glucose in glucose oxidase strips. The dyes should be used with caution because blue dye, in certain specific conditions, may be absorbed ${ }^{11-13}$. Methilene blue inhibits guanylate cyclase and FD\&C Blue $n^{\circ} 1$ dye is potentially inhibitor of mitochondrial res- piration in vitro ${ }^{12}$. There are suggestions regarding traditional clinical monitors of glucose oxidase strips and blue food coloring should no longer be used. Recently modified consensual approach recommends to consider the gastric residual volumes and identification of clinical factors that predispose to aspiration allowing to risk stratification and an algorhythm approach to the management of the critically ill patient on enteral tube feeding ${ }^{14}$.

It seems not reasonable to infer that gastric enteral nutrition in the ICU is safe and effective. On the opposite, the frequency of enteral nutrition gastrointestinal complications in the ICU is high and may, if persistent, expose the patients to undernutrition and even mortality $^{5}$. In a prospective cohort of 400 critically ill patients receiving enteral nutrition for nine days and fed through a nasogastric tube $(91 \%)$ with a standard polymeric diet $(66.2 \%)$ there were $62.8 \%$ of one or more gastrointestinal complications. High gastric residuals occurred in $39 \%$, diarrhea in $14.7 \%$, and abdominal distention in $13.2 \%$. The patients with gastrointestinal complications received less than $60 \%$ of the prescribed volume, had longer length of stay and higher mortality ${ }^{5}$.

It might be argued that fundamentally enteral nutrition in the ICU is a practical issue and cannot be discussed effectively without considering the severity of the patients, the frequency of ventilated patients, the pharmacologic drugs used as well as the alternative use of gastric prokinetic agents to increase gastric emptying in this setting ${ }^{13}$ and the alternatively use of jejunal feeding. However, efforts 
should be made in order to try to bring evidences to clinical practice. Recently, a meta analysis, encompassing 10 studies, compared the results of small bowel enteral feeding to gastric feeding. Small bowel feeding was associated with an increase in protein and calories delivered and a shorter time to target dose of nutrition. Compared with gastric feeding, small bowel feeding was associated with a reduc- tion in pneumonia. The authors concluded that small bowel feeding may be associated with a reduction in gastroesophageal regurgitation, an increase in nutrient delivery, a shorter time to achieve desired target nutrition, and a lower rate of ventilator-associated pneumonia ${ }^{15,16}$.

To provide adequate nutritional therapy for the ICU patients is of outmost necessity. Enteral nutrition, when appropriately indicated, is beneficial for the critically ill patient. Dr. Serpa and collaborators study shows that the administration of enteral feeding via stomach is associated with considerable morbidity and does not provide the nutritional needs for all patients. This observation should reinforce the substitution of nasogastric enteral nutrition for postpyloric tube feedings in critically ill adults.

See related article on page 9.

\section{REFERENCES}

1. SAITO H, TROCKI O, ALEXANDER JW et al. - The effect of route of administration on the nutritional state, catabolic hormone secretion, and gut mucosal integrity after burn injury. JPEN: J Parenter Enteral Nutrit 1987; 11: 1-71.

2. KUDSK KA, CROCE MA, FABIAN TC et al. - Enteral versus parenteral feeding: Effects on septic morbidity after blunt and penetrating abdominal trauma. Ann Surg 1992; 215: 503511 .

3. HADFIELD RJ, SINCLAIR DJ, HOULDSWORTH PE et al. Effects of enteral and parenteral nutrition on gut mucosal permeability in the critically ill. Am J Respir Crit Care Med 1995; 152: 1545-1548.

4. LIPMAN TO - Grains or veins: Is enteral nutrition really better than parenteral nutrition: A look at the evidence. JPEN: J Parenter Enteral Nutrit 1998; 22: 167-182.

5. MONTEJO JC - Enteral nutrition-related gastrointestinal complications in critically ill patients: A multicenter study. Crit Care Med 1999; 27: 1447-1453.

6. SERPA LF, KIMURA M, FAINTUCH J et al. - Effects of continuous versus bolus infusion of enteral nutrition in critical patients. Rev Hosp Clin Fac Med S Paulo 2003; 58 (1):9-14.
7. LEDEBOER M, MASCLEE AA, COENRAAD $M$ et al. Antroduodenal motility and small bowel transit during continuous intraduodenal or intragastric administration of enteral nutrition. Eur J Clin Invest 1999, 29(7):615-623.

8. VAN BERGE HENEGOUWEN M, AKKERMAN LMA, VAN GULIK TM et al. - Prospective, randomized trial on the effect of cyclic versus continuous enteral nutrition on postoperative gastric function after pylorus-preserving pancreatoduodenectomy. Ann Surg_1997, 226(6): 677 - 687.

9. LEVEIN NG, THORN SE, WATTWILL M - Dopamine delays gastric emptying and prolongs orocaecal transit time in volunteers. Eur J Anaesthesiol 1999, 16(4): 246 - 250.

10. MARTIGNONI M, FRIESS H, SELL F, RICKEN L et al: Enteral nutrition prolongs delayed gastric emptying in patients after whipple resection. Am J Surg 2000, 180(1) : 18 - 23 .

11. METHENY NA, CLOUSE RE - Bedside methods for detecting aspiration in tube-fed patients. Chest 1997; 111:724-731.

12. METHENY NA, NORMA A, DAH MS et al. - Efficacy of DyeStained Enteral Formula in Detecting Pulmonary Aspiration. Chest 2002, 122(1):276-281. 
13. MALONEY JP, BHARGAVA R, RYAN SL et al. - FD\&C Blue No.1 food dye is a mitochondrial poison that can be absorbed from enteral tube feedings in sepsis: a report of 3 deaths linked to systemic absorption [abstract]. JPEN: J Parenter Enteral Nutrit 2001; 25:S25.

14. MCCLAVE SA. DEMEO MT. DELEGGE MH. et al. North American Summit on Aspiration in the Critically Ill Patient: consensus statement. JPEN: J Parenter Enteral Nutrit 2002 26(6 Suppl):S80-5.
15. ZALOGA GP, MARIK P - Promotility agents in the intensive care unit. Crit Care Med 2000; 28: 2657-2659.

16. HEYLAND DK, DROVER JW,. DHALIWAL R. et al. - Optimizing the benefits and minimizing the risks of enteral nutrition in the critically ill: role of small bowel feeding. JPEN: J Parenter Enteral Nutrit 2002; 26(6 Suppl):S51-5; S56-7. 